\title{
Compreensão de enfermeiros de bordo sobre seu papel na equipe multiprofissional de transporte aeromédico
}

\author{
Flight nurses' comprehension about their role in the multiprofesional team of aero-medical transport
}

Compresión de enfermeros de bordo acerca de su papel en el equipo multiprofesional de transporte aeromédico

\author{
Dayane Reinhardt Scuissiato', Letícia Valois Boffi', Roseline da Rocha da Rocha', \\ Juliana Helena Montezeli", Michelle Taverna Bordin'", Aida Maris Peres ${ }^{\text {IV }}$ \\ ' Faculdade Evangélica do Paraná, Curso de Graduação em Enfermagem (Graduadas). Curitiba-PR, Brasil. \\ "Faculdade Evangélica do Paraná, Curso de Graduação em Enfermagem (Docente). Curitiba-PR, Brasil. Universidade \\ Federal do Paraná. Grupo de Pesquisa em Políticas, Gestão e Práticas de Saúde (Membro). Curitiba-PR, Brasil. \\ III Faculdades Integradas do Brasil, Curso de Enfermagem (Docente). Curitiba-PR, Brasil. \\ Iv Universidade Federal do Paraná, Programa de Pós-Graduação em Enfermagem. Grupo de Pesquisa em \\ Políticas, Gestão e Práticas de Saúde. Curitiba-PR, Brasil.
}

Submissão: 06-03-2011 Aprovação: 12-09-2012

\section{RESUMO}

Trata-se de um estudo qualitativo descritivo que objetivou identificar a compreensão de enfermeiros de bordo sobre seu papel na equipe multiprofissional de transporte aeromédico. Realizou-se entrevista semiestruturada com oito enfermeiros de bordo de Curitiba-PR, de junho a agosto de 2009. Os discursos foram submetidos a análise de conteúdo, emergindo três categorias. A primeira descreve as atribuições do enfermeiro de bordo como gestor da missão aeromédica, planejando o antes, o durante e após o transporte e incluindo o preparo da aeronave e o conhecimento do caso do paciente. Na segunda categoria são abordados aspectos deste profissional como prestador de assistência ao paciente aerorremovido; e, na terceira, descrevem-se a comunicação e o trabalho em equipe como competências fundamentais ao enfermeiro de bordo. Conclui-se que o enfermeiro no transporte aeromédico articula gerenciamento e cuidado em sua prática profissional por meio do uso de competências.

Descritores: Enfermagem; Transporte Aéreo de Pacientes; Papel Profissional.

\section{ABSTRACT}

This is a descriptive qualitative research which aimed at identifying the flight nurses' comprehension by about their role in the aero-medical multiprofesional team. A semi-structured interview was carried out with eight flight nurses from Curitiba-PR, from June to August 2009. The speeches were analyzed by the content analysis, from which three categories emerged. The first describes the responsibilities of the flight nurses as managers of the aero-medical mission, planning for before, during and after the transport, what includes the aircraft check-list and knowledge of the patient's case. The second category deals with aspects of these professionals as care providers to the aero-transferred patient. The third describes communication and team-work as fundamental requirements for flight nurses. It was concluded that the nurse in aero-medical team mixes management and caring in his/her professional practice by the use of specific competences.

Key words: Nursing; Air Ambulances; Professional Role.

\section{RESUMEN}

Se trata de un estudio cualitativo descriptivo que tiene como objetivo identificar la compresión de enfermeros de bordo acerca de su papel en el equipo multiprofesional de transporte aeromédico. Se realizó una entrevista semi estructurada con ocho enfermeros de bordo de Curitiba-PR, de junio a agosto de 2009. Los discursos fueron analizados por el análisis de contenido, emergiendo tres categorías. La primera describe sus atribuciones como gestor de la misión aeromédica, planeando el antes, durante y después del trasporte e incluyendo el preparo de la aeronave y el conocimiento del caso del paciente. En la segunda categoría son abordados los aspectos de este profesional como proveedor de asistencia al paciente removido por vía aérea; y, en la tercera, se describe la comunicación y el trabajo en equipo como competencias fundamentales del enfermero de bordo. Se concluye que el enfermero en el trasporte aeromédico articula gerencia y cuidado en su práctica profesional por medio del uso de competencias específicas. Palabras clave: Enfermería; Ambulancias Aéreas; Rol Profesional. 


\section{INTRODUÇÃO}

O Transporte Aeromédico é uma modalidade de deslocamento de paciente utilizada principalmente quando se fala de enfermos em estado crítico e, em muitas ocasiões, representa a única opção para que o indivíduo receba assistência em um centro especializado nas suas afecções ${ }^{(1)}$.

Sua origem advém de tempos remotos, principalmente das experiências de guerras relacionadas à necessidade de remover de maneira rápida os feridos das batalhas. Sua história teve início no ano de 1870, no campo militar, durante a Guerra Franco-Prussiana, quando soldados feridos foram retirados usando-se balões de ar quente. A eclosão da Primeira Guerra Mundial foi o marco histórico da assistência aos pacientes por meio aéreo, mas o atendimento de enfermagem no Transporte Aeromédico veio a ser implementado apenas na Segunda Guerra Mundial, ocasião em que os feridos eram removidos em aviões de carga, com três leitos de cada lado, assistidos por Flight Nurses, profissionais especializados nesse tipo de atendimento ${ }^{(2)}$.

Foi na segunda metade do século vinte que o Transporte Aeromédico apresentou um crescimento vertiginoso, em virtude dos avanços tecnológicos no campo da aviação e investimentos na capacitação de profissionais para atuarem nessa especialidade ${ }^{(3)}$.

No Brasil, essa atividade iniciou na década de 1960, ocasião em que a Força Aérea Brasileira introduziu o resgate com uso de helicópteros, especialmente para a busca de feridos de acidentes aeronáuticos. No meio civil, este tipo de atendimento teve início com a Petrobrás, Grupo de Socorro de Emergência do Corpo de Bombeiros do Rio de Janeiro e Grupamento de Rádio Patrulhamento Aéreo da Polícia Militar de São Paulo ${ }^{(3-4)}$. No início da década de 1990, emergiu a utilização do Transporte Aeromédico em larga escala, devido à necessidade apresentada por pacientes críticos na busca por um melhor tratamento e utilização de equipamentos mais avançados, aliada à globalização, que facilitou o acesso a esse serviço na área da saúde ${ }^{(4)}$.

A incessante busca pela qualidade reflete diretamente em diversas vertentes dos prestadores de assistência, e, desta maneira, os serviços de transporte aeromédico almejam cada vez mais o alcance da excelência. Nesse sentido, o aumento da frequência de remoção aérea de pacientes em estado crítico inspira a necessidade de desenvolvimento desta prática, inclusive rumo à busca de profissionais qualificados e especializados para atuarem na equipe multiprofissional de bordo, a qual é constituída pelo enfermeiro de bordo, o médico de bordo e o piloto.

Com relação à participação do enfermeiro nesta equipe, a Associação de Emergência de Enfermagem (Emergency Nurses Association) e a Associação Nacional de Enfermeiros de Bordo (National Flight Nurses Association), nos EUA, consideram fundamental que este profissional seja especificamente capacitado e com vasta experiência de atuação com pacientes $\operatorname{críticos}^{(4)}$.

No Brasil, a prática da enfermagem de bordo é amparada pela Lei $n^{\circ} 7.498 / 86$, que regulamenta o Exercício Profissional da Enfermagem. Nela, é estabelecido que é privativo do enfermeiro a organização e direção da assistência direta ao paciente crítico e onde sejam executadas atividades de maior complexidade técnica ${ }^{(5)}$.

Esta categoria profissional também encontra bases de cunho legal para sua atuação nesta especialidade na Portaria GM 2.048 de 5 de novembro de 2002, a qual determina, entre outros pontos referentes à temática, a capacitação específica dos profissionais de transporte aeromédico(6).

No entanto, não basta treinamento e respaldo legal para a garantia de uma atuação eficaz e eficiente deste profissional na especialidade em questão. O reconhecimento do enfermeiro acerca do papel que desempenha como membro da equipe multiprofissional de bordo contribui para a ocupação de qualidade de mais esse espaço de atuação.

Um estudo publicado recentemente destaca que existem lacunas na produção de conhecimento sobre o tema, salientando que as temáticas pouco abordam sobre a regulamentação no tocante às atribuições do enfermeiro do enfermeiro de bordo e recomenda a realização de investigações sobre a efetividade da assistência de enfermagem no transporte aéreo de pacientes ${ }^{(7)}$.

A história de tal atividade no Brasil justifica a escassez de estudos acerca da temática, o que demonstra a necessidade de preencher essa lacuna. Ademais, o transporte aeromédico é um recurso eficaz e valioso capaz de trazer benefícios para a assistência de pacientes nas regiões mais distantes do país ${ }^{(3)}$.

A partir das considerações até aqui colocadas, justifica-se a realização do presente estudo, na busca apresentar construtos que possam subsidiar uma prática consciente e transformadora por parte de enfermeiros de bordo, bem como colaborar para a visibilidade da enfermagem como peça fundamental no transporte aeromédico. Assim sendo, a pesquisa norteia-se pelo seguinte questionamento: Como enfermeiros de bordo caracterizam o seu papel na equipe multiprofissional de transporte aeromédico?

Para elucidar o problema de pesquisa, traçou-se como objetivo: Identificar a compreensão de enfermeiros de bordo acerca de seu papel na equipe multiprofissional de transporte aeromédico.

\section{METODOLOGIA}

O estudo foi realizado com base em abordagem qualitativa e descritiva, com a participação de oito enfermeiros de bordo que prestam serviços a três empresas, duas privadas e uma pública, de remoção aeromédica, da cidade de Curitiba-PR.

A seleção dos pesquisados deu-se em uma turma de Especialização Multiprofissional Lato Sensu em Transporte Aeromédico de uma universidade privada de Curitiba-PR. Usou-se como critérios de inclusão: ser enfermeiro e ter experiência mínima de um ano na área aeroespacial. Assim, de um total de 28 alunos, doze eram enfermeiros, dentre os quais oito se enquadraram como sujeitos e aceitaram participar da pesquisa.

A coleta de dados deu-se entre os meses de junho a agosto de 2009 por técnica de entrevista semiestruturada, gravada em áudio. $\mathrm{O}$ instrumento norteador das entrevistas foi composto por quatro questões abertas que visaram alcançar o objetivo do estudo. 
Os dados foram obtidos após aprovação do projeto pelo Comitê de Ética em Pesquisa da Sociedade Evangélica Beneficente sob o protocolo de $n^{\circ}$. 3864/09, CAAE 0060.0.081.000-09 e com assinatura de um termo de consentimento livre e esclarecido pelos sujeitos com as informações da referida pesquisa.

Após a transcrição das falas obtidas com as entrevistas, os dados foram submetidos à análise de conteúdo proposta por Bardin ${ }^{(8)}$, obedecendo às etapas de pré-análise, exploração e tratamento dos resultados. A partir da emersão das categorias, realizaram-se discussões pautadas na literatura para fundamentar as reflexões e exemplificadas com trechos das falas dos sujeitos codificados como EE1, EE2, EE8.

\section{RESULTADOS E DISCUSSÃO}

A análise de conteúdo identificou as seguintes categorias: O enfermeiro gestor da missão aeromédica; $O$ enfermeiro prestador de assistência ao paciente na missão aeromédica; e Competências fundamentais do enfermeiro de bordo.

\section{A. $O$ enfermeiro gestor da missão aeromédica}

O processo de trabalho do enfermeiro é composto por diferentes subprocessos, como assistir, administrar/gerenciar, ensinar, pesquisar e participar politicamente ${ }^{(9)}$. Assim, o gerenciamento faz parte da atuação deste profissional como elemento fundamental para garantia de uma assistência de enfermagem de qualidade, já que os subprocessos possuem articulação entre si.

A importância da atividade gerencial do enfermeiro no contexto do transporte aeromédico é reconhecida pelos pesquisados, principalmente no que concerne ao planejamento da missão, como ilustrado pelos seguintes trechos:

O enfermeiro vai desempenhar desde a parte da triagem, saber o que o paciente precisa, pra você montar a aeronave [...] vai deixar o material de acordo com aquela patologia apresentada pelo paciente. É preciso fazer uma logística antes da decolagem, normalmente associado com o médico. EE1

Todo o material, a conferência, a checagem, a troca, a reposição, o cuidado, a validade, a antissepsia, tudo é função do enfermeiro. EE5

As atribuições desenvolvidas no transporte aeromédico fundamentam-se na fisiologia do voo, agregando-se à experiência conquistada de cada enfermeiro em outras instituições de trabalho, que tenham proporcionado conhecimento mínimo em remoção aeromédica. Essas atividades estão dividas em três etapas: pré-transporte; transporte propriamente dito e pós-transporte ${ }^{(4)}$. Assim, o gerenciamento realizado pelo enfermeiro de bordo permeia essas etapas e é desenvolvido em consonância com os outros membros da equipe, a começar pela escolha da aeronave a ser utilizada.

Os critérios logísticos de escolha do meio de transporte aéreo mais eficaz para o caso são coerentes com as particularidades do atendimento, levando em conta: alcance, comunicação no transporte, condições meteorológicas, custo, disponibilidade de ambulância, equipamentos e materiais, espaço da cabine, exigências de treinamento de pessoal, exigências especiais para o transporte, resposta a desastres, segurança no transporte, tempo de resposta e triagem clínica do caso, com observação da patologia, da evolução clínica e do custo-benefício do transporte em cada atendimento ${ }^{(10)}$.

Ainda na fase pré-transporte, existe a necessidade de prever e prover os materiais e equipamentos a serem utilizados na missão, pois a configuração interna é bastante variável, dependendo do tipo da aeronave ${ }^{(2)}$. Médico e enfermeiro devem realizar em conjunto a organização dos equipamentos, materiais e medicamentos, estabelecendo sua disposição na aeronave e definindo a composição mínima necessária para oferecer uma remoção segura e de qualidade aos pacientes ${ }^{(4)}$. A atenção com os materiais e equipamentos destinados à missão é mencionada pelos sujeitos da pesquisa:

O enfermeiro tem que deixar a aeronave toda pronta antes do voo, e para isso utiliza-se de um check-list para fazer a conferência de todos os materiais e medicamentos que poderão ser utilizados. (EE6)

... desde a preparação da aeronave de acordo com o tipo do paciente a ser transportado nessa missão, selecionando assim todos os materiais que serão e poderão ser utilizados durante o voo, saber como está o clima, o tipo de aeronave que será utilizado, pois se é um transporte com trajeto curto vai utilizar um tipo de aeronave... (EE7)

A quantidade dos equipamentos, materiais e medicações utilizadas, bem como suas seleções, pautam-se no grau de assistência que o paciente requeira, ou seja, quanto mais grave o paciente, quanto maior a quantidade de problemas que possam advir de sua patologia, maior a especificidade e o número de equipamentos. Todos devem estar em perfeitas condições de uso, devendo-se considerar ainda, a idade, a gravidade do estado e a indicação da remoção do paciente ${ }^{(2)}$.

Uma vez sanada a fase de pré-transporte, o enfermeiro concentra-se nas necessidades assistenciais do paciente durante o voo. É preciso, contudo, ressaltar que o transporte propriamente dito compreende todo o trajeto hospital-aeronave-hospital e a assistência ao cliente ${ }^{(4)}$.

Esta etapa obterá sucesso quanto melhor organizada for a etapa anterior e este fato é reconhecido pelos enfermeiros de bordo entrevistados:

O transporte ótimo é aquele em que a gente não tem que fazer nada durante o transporte. A gente faz tudo praticamente. EE3

A finalização da missão aeromédica é efetivada não apenas com a entrega do paciente à instituição destino, mas sim, a partir do momento em que tanto a equipe quanto os meios utilizados estão aptos a um novo transporte. Nesta última etapa, são realizadas a organização e reposição tanto da aeronave quanto da ambulância (quando utilizada) que deverão estar prontas para uma nova missão ${ }^{(4)}$. 
Nesta fase, cabe ao enfermeiro de bordo repor os materiais utilizados, registrar dados do paciente, organizar o prontuário, solicitar limpeza da aeronave, fazer a desinfecção dos materiais, encaminhar materiais para esterilização e roupas usadas para a lavanderia ${ }^{(4)}$.

Estas atividades são pontuadas pelos participantes da investigação, como pode ser verificado nas colocações a seguir:

Terminando o transporte o enfermeiro deve realizar a desinfecção da aeronave, repor os materiais utilizados, deixar tudo em ordem, para não perder tempo numa próxima missão. EE6

No pós-transporte, o enfermeiro realiza a desinfecção da aeronave, dos materiais utilizados, repõe os mesmos, de forma que a aeronave fique pronta para próxima missão. EE7

... ainda tenho o cuidado com a organização dos equipamentos, materiais, medicamento, relatórios de transportes, escala das equipes e treinamentos. EE8

Identificou-se o cuidado como foco das atividades gerenciais desempenhadas antes, durante e após o transporte aeromédico pelos enfermeiros de bordo do estudo. Isto converge com a questão de que o cuidar e o gerenciar são subprocessos complementares que constituem o processo de trabalho do enfermeiro, não sendo viável dicotomizá-los. Assim, o cuidado é reconhecido como fim, possível e necessário de ser gerenciado ${ }^{(11)}$.

Passa-se, na categoria a seguir, a discorrer sobre o enfermeiro de bordo no processo cuidativo propriamente dito.

\section{B. O enfermeiro prestador de assistência ao paciente na missão aeromédica}

A preocupação com o cuidado ao paciente a ser transportado é tida pelos enfermeiros de bordo desde o momento do planejamento da aeronave até a chegada do mesmo no serviço destino. Os sujeitos da pesquisa salientaram a importância de se conhecer o indivíduo no concernente ao seu caso clínico para analisar a viabilidade ou não do voo, como percebido no seguinte trecho:

Chegando ao hospital de origem você vai conversar com a enfermagem, saber o que o paciente tem, fazer parte junto para saber se ele está estável, verificar os dados vitais para decidir se é recomendado mesmo o voo. EE1

A necessidade de uma avaliação minuciosa, assim como a estabilização do paciente são, certamente, prioridades da equipe de remoção, que deve estar familiarizada com os principais distúrbios respiratórios, cardiovasculares, metabólicos e neurológicos que podem atuar como fatores negativos durante o transporte ${ }^{(10)}$.

Faz-se, a este ponto, uma aproximação com a Sistematização da Assistência de Enfermagem (SAE) como instrumento a ser utilizado no cenário do Transporte Aeromédico. A SAE é uma atividade privativa do enfermeiro, conforme dispõe o Art. 11 da Lei $n^{\circ}$. 7.498 de 25 de junho de 1986, referente ao Exercício
Profissional da Enfermagem e a Resolução 358/2009 do COFEN de 15 de outubro de 2009, que permite realizar a identificação das situações de saúde e doença, subsidiando a prescrição e a implementação das ações de assistência de enfermagem ${ }^{(5 ; 12)}$.

As características deste tipo de serviço requerem a realização da SAE com especificidades que diferem das demais ambiências de inserção do enfermeiro, tendo início no pré-voo, continuando durante o voo e tendo sua finalização na entrega no paciente em seu destino. Ainda que os pesquisados não tenham mencionado a SAE em todas as suas etapas como sendo de execução no seu cotidiano, a fala anterior nos remete a uma de suas fases, o histórico de enfermagem, conceituado como o levantamento de dados do ser humano que são significativos para que o enfermeiro identifique seus problemas e, consequentemente, planeje a assistência a ser prestada ${ }^{(13)}$.

A importância desta fase da SAE fica também evidenciada na seguinte colocação dos enfermeiros participantes do estudo:

A falta de informação sobre o caso clínico "real" do paciente atrapalha o planejamento e andamento da remoção. EE8

Assim, mesmo que fragmentada, a SAE permite a avaliação do paciente pelo enfermeiro antes da remoção, o que possibilita o planejamento da assistência, oferece informações sobre a evolução clínica durante a remoção e pode servir como fonte de dados para o hospital de destino, facilitando o estabelecimento do plano de cuidados e prognóstico ${ }^{(2)}$.

Outro aspecto salientado pelos sujeitos se refere à enfermagem como elemento facilitador para a humanização durante o Transporte Aeromédico, como visto nestas falas:

Eu vejo assim: que hoje o enfermeiro na nossa equipe tem uma função bastante importante que é uma visão humana, [...] o produto final é a satisfação do nosso cliente. EE2

O olhar do enfermeiro é muito diferente do médico, é muito diferente do piloto. O enfermeiro tem um foco muito humano, muito maior do que qualquer um desses profissionais, eu acho que isso também faz muito a diferença do atendimento. EE4

Tais colocações encontram afinidade com o fato da enfermagem ser uma profissão que alia ciência e arte e, portanto, além dos aspectos técnicos, caracteriza-se pela expressão estética $^{(4)}$. Assim, a arte na Enfermagem é a forma como o conhecimento, o julgamento e a habilidade são utilizados na área clínica ${ }^{(14)}$. Na Enfermagem, o padrão de conhecimento estético corresponde à sua arte, a qual é expressiva, subjetiva e tem visibilidade no ato de cuidar, relacionando-se à prática profissional expressa na relação enfermeiro-cliente ${ }^{(15)}$.

Mesmo com esta percepção da abordagem estética da profissão, os enfermeiros não deixam de enfatizar o conhecimento científico como essencial à sua prática no Transporte Aeromédico, como pontuam as falas a seguir:

[...] o preparo deste profissional é muito importante, tem uma série de coisas que o enfermeiro toma a frente, como a 
busca pelo posicionamento do paciente dentro da aeronave, se o paciente vai estar com a cabeceira elevada ou não, por exemplo. Isso exige conhecimento específico. EE4

[...] todo o conhecimento técnico é fundamental, com alguns cursos, algum estudo a mais, principalmente pós-graduação que hoje existe, pra você aprimorar ainda mais isto, então acaba facilitando muito a vida do enfermeiro nessa questão do Transporte Aeromédico. EE3

Portanto, muitos são os conhecimentos requeridos do enfermeiro de bordo e estes sustentam habilidades e atitudes articuladas na prática cuidativa.

\section{Competências fundamentais do enfermeiro de bordo}

Competências podem ser compreendidas como mobilização de conhecimentos, habilidades e atitudes no âmbito laboral ${ }^{(16)}$. Os enfermeiros de bordo referiram como sendo as principais competências deles requeridas: a comunicação e o trabalho em equipe.

\section{Comunicação}

Na remoção aeromédica, um aspecto importante é o relacionamento com o público e com diferentes profissionais. O enfermeiro de bordo tem contato com várias pessoas durante a transferência do paciente a ele confiado em situações adversas, devendo estabelecer um contato tranquilo e seguro, como também o sigilo profissional necessário a

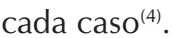

O depoimento aqui utilizado como exemplo ilustra esta questão e coaduna com a literatura:

[...] é bastante importante você chegar ao hospital e trazer muitas informações: olha, o paciente, o nosso cliente, nos passou essas informações, nós coletamos outras informações do hospital onde ele estava, isso vai se somando [...] Então é assim, eu sou um dos elos que é formado pelo médico, enfermeiro, piloto, as pessoas que nos auxiliam em pista também, então unindo todos esses elos, nós possamos chegar a uma forma mais concreta de trazer essa satisfação tanto para a gente, quanto para o nosso paciente. EE2

A equipe de transporte deve obter o maior número de informações sobre o paciente, para poder avaliá-lo e prepará-lo para remoção. Após sua avaliação, a equipe informa o hospital de destino sobre os elementos necessários para a recepção do aerorremovido. O hospital envia uma ambulância no horário previsto para pouso da aeronave no aeroporto e esta transporta o paciente à instituição. Ao chegar ao hospital, o enfermeiro de bordo realiza a passagem de informações sobre o paciente e a entrega do relatório de enfermagem ao enfermeiro responsável pelo paciente transportado ${ }^{(2)}$.

A comunicação é um importante instrumento gerencial, cria uma linguagem única que expressa os conceitos de várias disciplinas. Portanto, a comunicação gera interação dos saberes e, simbolicamente, por meio da linguagem, questionam-se e trocam-se informações que contribuem para formação de um projeto comum ${ }^{(17)}$.

Nesse sentido, o enfermeiro mostra-se como articulador entre os diferentes profissionais, uma vez que a comunicação é uma competência construída desde a sua formação acadêmica, considerando seus papéis como elementos constituintes da equipe multiprofissional e a falha da mesma entre os envolvidos no transporte aeromédico pode dificultar o percurso do atendimento do cliente.

A comunicação é considerada uma ferramenta poderosa, um elo de ligação entre as diferentes disciplinas, uma vez que as diferentes técnicas possibilitam contribuição da dimensão de trabalho, de forma a melhorar os serviços prestados, mas sem abolir as especificidades de cada profissional ${ }^{(17 ; 18)}$.

\section{Trabalho em Equipe}

O trabalho em equipe é uma modalidade de trabalho coletivo que consiste na relação recíproca entre as intervenções técnicas e a interação dos agentes, de forma a construir um projeto assistencial comum, formando assim a integração do mesmo ${ }^{(18)}$.

No Transporte Aeromédico, a sintonia do trabalho em equipe, com cada membro exercendo funções participativas a bordo a fim de garantir um consenso nas situações rotineiras e/ou emergenciais ${ }^{(10)}$ é mencionado pelos pesquisados como facilitador em sua atuação:

O que poderia pontuar de facilidade é ter um bom relacionamento com a equipe, ter um [...] o entrosamento com a equipe facilita muito o atendimento. EE5

[...] a parte que facilita eu acho que é essa sintonia [...] não existe o degrau entre o médico e o enfermeiro, todo mundo tem que estar orientado de todas as coisas EE4

Costumo dizer que a equipe em transporte passa a ser uma pessoa só. Quando confiamos e estamos acostumados à dupla de voo, tudo flui melhor, não é preciso falar, simplesmente olhar. EE8

O trabalho em equipe trata-se de uma prática fundamental para o sucesso da assistência à saúde, a qual, por ser um processo dinâmico e complexo, necessita de reflexões interdisciplinares para sua compreensão e sustentação de uma nova prática $^{(19)}$. Desde os filósofos gregos, a ideia de interdisciplinaridade visa à criação do homem integral, buscando unir os conhecimentos que vão se fragmentando para construção de um saber que dê conta da totalidade, de uma perspectiva pluralista e heterogênea, com olhar diferenciado ${ }^{(19)}$.

No campo da saúde, muitas vezes cria-se uma visão corporativa, disciplinar e unidimensional de forma a não explicar o processo saúde-doença com base na totalidade do indivíduo. Porém, ao estabelece-se a relação de interdisciplinaridade, tem-se a possibilidade de contextualizar o conhecimento de forma a enfrentar melhor as complexidades, já que envolvem mudanças. Assim, o trabalho em equipe permite intervenções que abordem várias dimensões da vida social ${ }^{(19)}$. 
Ainda que o crescimento dos conhecimentos e formas de intervenção culminem em uma especialização excessiva e, por conseguinte, na visão reducionista do ser humano em diversos outros cenários de assistência à saúde, no Transporte Aeromédico não há espaço para essa mentalidade linear de atuação profissional ${ }^{(17)}$.

É fato que a dificuldade de se criar um trabalho interdisciplinar possivelmente faça parte de todos profissionais da equipe de saúde, visto que implica na especificidade das atribuições de cada profissão, do seu saber e até que ponto se deve aprofundar no trabalho em conjunto, de forma cooperativa ${ }^{(17)}$. Entretanto, os enfermeiros de bordo entrevistados possuem um discurso que caminha para a percepção da necessidade de uma prática multiprofissional e interdisciplinar, como percebido nesta fala:

[...] o trabalho é um trabalho muito conscientizado da importância de cada um, e que cada um faz um trabalho singular dentro daquela equipe, pra que tudo funcione direito, e se a gente buscar o trabalho individualizado não funciona, todo mundo sabe que é fundamental o trabalho de cada um, mas que todo mundo tem seu papel fundamentado naquele processo. Então ninguém trabaIha sozinha, mas todo mundo sabe a função do outro. Não existe peso maior ou outro tipo de palavra que caracterize qualquer um dos profissionais, todo mundo tem o seu valor. EE4

Nota-se que os participantes do estudo mostram-se cônscios de suas responsabilidades e atribuições, porém buscam articulá-las aos saberes dos demais membros da equipe em prol de uma assistência ao paciente em sua totalidade.

\section{CONSIDERAÇÕES FINAIS}

Tendo em vista o objetivo proposto, foi possível identificar a compreensão que enfermeiros de bordo possuem acerca de seu papel na equipe multiprofissional de transporte aeromédico.

Os achados desta investigação permitem afirmar que o enfermeiro do Transporte Aeromédico destaca-se como elemento que atua com uma visão hologramática da equipe no atendimento à totalidade das necessidades de saúde do indivíduo. Sua prática profissional deve ultrapassar as bases mecânicas, agregando a expressão e a subjetividade na realização do cuidado.

Neste campo de ação, a interdisciplinaridade é componente fundamental. Contudo, a discussão sobre a interdisciplinaridade na área da saúde, principalmente na enfermagem, ainda é incipiente diante da jornada que conduz ao rompimento do paradigma reducionista vigente.

Deste modo, o enfermeiro, como membro da equipe multiprofissional de saúde que transporta pacientes por meio de aeronaves, defronta-se com demandas e desafios que requerem deste profissional competências que o respaldem em situações adversas e independência nas tomadas de decisões, além de alto grau de conhecimento, atitudes e habilidades específicas para exercer esta função.

O transporte aeromédico é uma das mais significativas aquisições da aviação. De origem militar, para soldados feridos em combate, teve nas guerras períodos marcantes de impulso tecnológico. O que foi aprendido nos campos de guerra e transposto para a medicina civil permite a utilização crescente deste recurso. Diante disto, espera-se que os conhecimentos produzidos com esta pesquisa, ainda que embrionários, instiguem enfermeiros de bordo à reflexão de sua prática e sirvam de subsídios para outros estudos que abarquem esta temática.

\section{REFERÊNCIAS}

1. Hernández NM, Olivera CER. Transporte aeromédico del paciente crítico. Rev Asoc Med Crit Ter Intensiva 2007; 21(4):200-6.

2. Gentil RC. Aspectos históricos e organizacionais da remoção aeromédica: a dinâmica da assistência de enfermagem. Rev Esc Enferm USP 1997;31(3):452-67.

3. Acuña FG, Márquez EC. Transporte aeromédico: ficción y realidad. Trauma 2001;4(2):70-6.

4. Thomaz RR, Miranda MFB, Souza GAG, Gentil RC. Enfermeiro de bordo: uma profissão no ar. Acta Paul Enferm 1999;12(1):86-96.

5. Brasil. Lei n. 7.498, de 25 de junho de 1986. Dispõe sobre a regulamentação do exercício da enfermagem e dá outras providências. Diário Oficial da União 26 jun 1986. Seção 1.

6. Ministério da Saúde (Brasil) Portaria n. ${ }^{\circ}$ 2048/GM de 5 de novembro de 2002. Aprova o Regulamento do Sistema Único de Saúde (SUS). [portaria na internet] Diário Oficial da União 4 nov 2002 [acesso em 15 jul 2010]. Disponível em: < http://portal.saude.gov.br/portal/arquivos/pdf/regulamento_sus_240909.pdf >

7. Passos IPBD, Toledo VP, Duran ECM. Transporte aéreo de pacientes: análise do conhecimento científico. Rev Bras Enferm 2011;64(6):1127-31.

8. Bardin L. Análise de conteúdo. Lisboa: Edições 70; 2002.

9. Sanna MC. Os processos de trabalho em enfermagem. Rev Bras Enferm 2007;60(2):221-4.

10. Guimarães JI. Diretriz de doença cardiovascular e viagem aérea: noções de transporte aeromédico. [artigo na internet]; [acesso em 24 out 2010]. Disponível em: < http:// publicacoes.cardiol.br/consenso/2003/site/049.pdf>

11. Rossi FR, Lima MADS. Fundamentos para processos gerenciais na prática de cuidado. Rev Esc Enferm USP 2005;39(4):460-8.

12. Brasil. Conselho Federal de Enfermagem: Resolução n. 
358, de 15 de outubro de 2009. Dispõe sobre a SAE e a implementação do processo de enfermagem. Diário Oficial da União 23 out 2009.

13. Horta WA. Processo de enfermagem. São Paulo: EPU; 1979.

14. Cestari ME. Padrões de conhecimento de Enfermagem e suas implicações no ensino. Rev Gaúch Enferm 2003;24(1):34-41.

15. Silva LWS et al. Arte na Enfermagem: iniciando um diálogo reflexivo. Texto \& Contexto Enferm 2005; 14(1):120-3.
16. Fleury MTL, Fleury A. Construindo o conceito de competência. RAC 2001;(n. ${ }^{\circ}$ esp):181-96.

17. Rocha RM. O Enfermeiro na Equipe Interdisciplinar do Centro de Atenção Psicossocial e as possibilidades de cuidar. Texto Contexto \& Enferm 2005;14(3):350-7.

18. Peduzzi M. Equipe Multiprofissional de Saúde: conceito e tipologia. Rev Saúde Pública 2001;35(1):103-9.

19. Meirelles BHS. A Interdisciplinaridade como construção do conhecimento em saúde e Enfermagem. Texto \& Contexto Enferm 2005;14(3):411-8. 